\title{
Gallium-68-labeled anti-HER2 single-chain Fv fragment: development and in vivo monitoring of HER2 expression.
}

\section{$\operatorname{AUTHOR}(\mathrm{S}):$}

Ueda, Masashi; Hisada, Hayato; Temma, Takashi; Shimizu, Yoichi; Kimura, Hiroyuki; Ono, Masahiro; Nakamoto, Yuji; Togashi, Kaori; Saji, Hideo

\section{CITATION:}

Ueda, Masashi ...[et al]. Gallium-68-labeled anti-HER2 single-chain Fv fragment: development and in vivo monitoring of HER2 expression.. Molecular imaging and biology 2015, 17(1): 102-110

\section{ISSUE DATE:}

2015-02

URL:

http://hdl.handle.net/2433/202106

\section{RIGHT:}

The final publication is available at Springer via http://dx.doi.org/10.1007/s11307-014-0769-5.; The full-text file will be made open to the public on 22 July 2015 in accordance with publisher's 'Terms and Conditions for Self-Archiving':; この 論文は出版社版でありません。引用の際には出版社版をご確認ご利用ください。; This is not the published version. Please cite only the published version. 


\section{Title Page}

Gallium-68-labeled anti-HER2 single chain Fv fragment: Development and in vivo monitoring of HER2 expression

Masashi Ueda ${ }^{1,2, a}$, Hayato Hisada ${ }^{2}$, Takashi Temma ${ }^{2}$, Yoichi Shimizu ${ }^{2,3}$, Hiroyuki Kimura ${ }^{2,4}$, Masahiro Ono $^{2}$, Yuji Nakamoto ${ }^{5}$, Kaori Togashi ${ }^{5}$, Hideo Saji $^{2, *}$

${ }^{1}$ Radioisotopes Research Laboratory, Kyoto University Hospital, Faculty of Medicine, Kyoto University, Kyoto 606-8507, Japan

${ }^{2}$ Department of Patho-Functional Bioanalysis, Graduate School of Pharmaceutical Sciences, Kyoto University, Kyoto 606-8501, Japan

${ }^{3}$ Central Institute of Isotope Science, Hokkaido University, Sapporo 060-0815, Japan

${ }^{4}$ Radioisotope Research Center of Kyoto University, Kyoto 606-8501, Japan

${ }^{5}$ Department of Nuclear Medicine and Diagnostic Imaging, Graduate School of Medicine, Kyoto University, Kyoto 606-8507, Japan

${ }^{\text {a }}$ Present address: Department of Pharmaceutical Analytical Chemistry, Graduate School of Medicine, Dentistry, and Pharmaceutical Sciences, Okayama University, Okayama 700-8530, Japan 


\section{Corresponding author:}

Hideo Saji, Ph.D.

Department of Patho-Functional Bioanalysis

Graduate School of Pharmaceutical Sciences

Kyoto University

46-29 Yoshida Shimoadachi-cho, Sakyo-ku, Kyoto 606-8501, Japan

Phone: +81-75-753-4556; Fax: +81-75-753-4568

E-mail: hsaji@pharm.kyoto-u.ac.jp

\section{Running title:}

Gallium-68-labeled anti-HER2 single chain Fv fragment

\section{Manuscript category:}

Article 


\begin{abstract}
Purpose

We aimed to develop a ${ }^{68} \mathrm{Ga}$-labeled single-chain variable fragment ( $\mathrm{scFv}$ ) targeting the human epidermal growth factor receptor 2 (HER2) to rapidly and noninvasively evaluate the status of HER2 expression
\end{abstract}

\title{
Procedures
}

Anti-HER2 scFv was labeled with ${ }^{68} \mathrm{Ga}$ by using deferoxamine (Df) as a bifunctional chelate. Biodistribution of ${ }^{68} \mathrm{Ga}$-Df-anti-HER2 $\mathrm{scFv}$ was examined with tumor-bearing mice and positron emission tomography (PET) imaging was performed. The changes in HER2 expression after anti-HER2 therapy were monitored by PET imaging.

Results

${ }^{68} \mathrm{Ga}$-Df-anti-HER2 scFv was obtained with high radiochemical yield after only 5-min reaction at room temperature. The probe showed high accumulation in HER2-positive xenografts and the intratumoral distribution of radioactivity coincided with HER2-positive regions. Furthermore, ${ }^{68} \mathrm{Ga}$-Df-anti-HER2 scFv helped visualize HER2-positive xenografts and monitor the changes in HER2 expression after anti-HER2 therapy.

\section{Conclusion}

${ }^{68} \mathrm{Ga}$-Df-anti-HER2 scFv could be a promising probe to evaluate HER2 status by in vivo PET imaging, unless trastuzumab is prescribed as part of the therapy. 


\section{Key words:}

Human epidermal growth factor receptor 2 (HER2); Single-chain Fv Fragment (scFv); Gallium-68;

Positron Emission Tomography (PET); 17-DMAG; Therapy 


\section{Introduction}

The human epidermal growth factor receptor 2 (HER2) is a member of ErbB family of receptor tyrosine kinases. Excessive HER2 signaling due to receptor overexpression is a hallmark of a wide variety of solid tumors, such as breast, gastric, and ovarian carcinomas [1-3]. Although overexpression of HER2 is related to aggressiveness and poor prognosis, trastuzumab, a recombinant monoclonal antibody against HER2 has positively influenced the prognosis of patients with HER2-positive breast cancer [4]. Thus, accurate assessment of HER2 status is essential to select the patients who may benefit from the anti-HER2 therapy. HER2 status is routinely determined by immunohistochemistry and/or fluorescence in situ hybridization, by using biopsy specimens in clinical practice [5]. However, the HER2 status in the biopsy specimens is not always representative of the whole tumor because of sampling bias and intratumoral heterogeneity [6]. Moreover, a relatively high discordance in HER2 expression in primary versus metastatic lesions has been reported [7], indicating a strong need for the reassessment of HER2 status associated with disease progression. Repetitive biopsy impairs the quality of life of the patients because of the invasiveness of the procedure.

Radionuclide molecular imaging of HER2 can help avoid biopsy-associated issues, because this technique is noninvasive, quantitative, and directed to the whole body [8]. Clinical studies employing positron emission tomography (PET) by using trastuzumab radiolabeled with

${ }^{64} \mathrm{Cu}$ and ${ }^{89} \mathrm{Zr}$ have been reported previously [9, 10]. Both probes visualized most of the known 
lesions and some that had been undetected earlier. These results indicate that nuclear medicine imaging of HER2 is effective, as expected. However, the large molecular weight of trastuzumab (148 $\mathrm{kDa}$ ) leads to some imaging problems due to the long biodistribution time, slow tumor penetration, and slow blood clearance of the tracers, which in turn reduces target to non-target contrast. Therefore, several types of radiolabeled trastuzumab fragments such as $\mathrm{F}\left(\mathrm{ab}^{\prime}\right)$ [11], diabody [12], and minibody [13] have been developed to fasten blood clearance and obtain successful HER2-positive tumor imaging. Nevertheless, there are no reports on the visualization of HER2-positive tumor in vivo by using radiolabeled single-chain Fv fragment (scFv).

Since scFv shows rapid distribution and clearance, radionuclides with short half-lives are preferable for radiolabeling to reduce the radiation exposure of patients. Gallium-68 (half-life: 1.13 h), a metallic positron emitter, is one such radionuclide. Moreover, ${ }^{68}$ Ga-labeled radiopharmaceuticals have high clinical availability, because they can be obtained from the ${ }^{68} \mathrm{Ge} /{ }^{68} \mathrm{Ga}$ generator and their use does not require a cyclotron on site [14]. A variety of chelators have been developed to allow the formation of stable ${ }^{68} \mathrm{Ga}$ complexes such as 1,4,7,10-tetraazacyclododecane- $N, N^{\prime}, N^{\prime \prime}, N^{\prime \prime \prime}$-tetraacetic acid (DOTA). However, because ${ }^{68} \mathrm{Ga}$-DOTA complexes need heat or long incubation to react, they are not suitable for rapid radiolabeling with biopharmaceuticals. On the other hand, $p$-isothiocyanatobenzyl derivative of deferoxamine (Df- $p$-SCN) is a convenient bifunctional chelate for labeling proteins at room temperature with ${ }^{68} \mathrm{Ga}$. This implies that $\mathrm{scFv}$ can maintain its immunoactivity during all reactions. 
For this reason, we selected Df- $p$-SCN as a ${ }^{68}$ Ga-chelator. Although Df-conjugated antibody [15] and nanobody [16] have recently been reported, to the best of our knowledge, there has been no report on their application to $\mathrm{scFv}$.

In this study, we developed ${ }^{67 / 68} \mathrm{Ga}$-labeled Df-anti HER2 $\mathrm{scFv}$ to achieve faster blood clearance and better tumor-to-blood ratio at an early time point relative to that of trastuzumab. Furthermore, the changes in the expression levels of HER2 after treatment with 17-dimethylaminoethylamino-17-demethoxygeldanamycin (17-DMAG), which destabilizes HER2 protein, were monitored by using this probe.

\section{Experimental Procedures}

Preparation of Deferoxamine-conjugated anti-HER2 scFv (Df-anti-HER2 scFv) and non-radioactive Ga-Df-anti-HER2 scFv

Anti-HER2 scFv (4D5-C10) with a COOH-terminal cysteine was a kind gift from CANON Inc. (Tokyo, Japan). The purity of anti-HER2 scFv (4D5-C10) was determined by sodium dodecylsulfate-polyacrylamide gel electrophoresis and Coomassie staining. The $p$-isothiocyanatobenzyl derivative of deferoxamine (Df- $p$-SCN) was purchased from Macrocyclics, Inc. (Dallas, Tx).

The scFv was incubated with Df- $p$-SCN (3 eq., $12 \mu \mathrm{L}$ in dimethyl sulfoxide) at $37^{\circ} \mathrm{C}$ for 30 
min, in a total volume of $0.8 \mathrm{~mL}$ of $50 \mathrm{mM} \mathrm{NaHCO}_{3}$. Nonconjugated chelate was removed by size exclusion chromatography using a PD-10 column (GE Healthcare Bio-Science AB, Uppsala, Sweden) with $0.25 \mathrm{M} \mathrm{NaOAc}(\mathrm{pH}$ 5.5) as the eluent. The Df-anti-HER2 scFv was collected and concentrated by ultrafiltration (Amicon 10-kDa cut-off device; Millipore Corporation, Billerica, MA).

Non-radioactive $\mathrm{GaCl}_{3}$ was added to $3 \mathrm{M} \mathrm{NH}_{4} \mathrm{OAc}$ to form Ga-acetate. Df-anti-HER2 scFv was incubated with Ga-acetate (10 eq., $7.3 \mu \mathrm{L}$ in $\left.3 \mathrm{M} \mathrm{NH}_{4} \mathrm{OAc}\right)$ at $37^{\circ} \mathrm{C}$ for $35 \mathrm{~min}$, in a total volume of $0.5 \mathrm{~mL}$ of $0.25 \mathrm{M} \mathrm{NaOAc}(\mathrm{pH} 5.5)$. Following purification using the PD-10 column, Ga-Df-anti-HER2 scFv was collected and concentrated by ultrafiltration.

The molecular weight of anti-HER2 scFv, Df-anti-HER2 scFv, and Ga-Df-anti-HER2 scFv was determined by matrix-assisted laser desorption/ionization mass spectrometry (4800 Plus MALDI TOF/TOFTM Analyzer; AB SCIEX; Framingham, MA).

Preparation of ${ }^{67 / 68}$ Ga-Df-anti-HER2 scFv

${ }^{67} \mathrm{GaCl}_{3}$ was kindly provided by FUJIFILM RI Pharma Co., Ltd. (Tokyo, Japan). ${ }^{68} \mathrm{Ge} /{ }^{68} \mathrm{Ga}$ generator was purchased from Eckert \& Ziegler Isotope Products GmbH (Berlin, Germany).

${ }^{67} \mathrm{GaCl}_{3}$ was mixed with $3 \mathrm{M} \mathrm{NH} \mathrm{NH}_{4} \mathrm{OAc}$ and incubated for at least 5 min to facilitate ${ }^{67} \mathrm{Ga}$-acetate chelation. ${ }^{68} \mathrm{Ga}$ was eluted from the generator and was concentrated using an anion exchange column (Chromafix, Macherey-Nagel GmbH \& Co., Düren, Germany) [16]. The eluent 
from the anion exchange column was mixed with $3 \mathrm{M} \mathrm{NH}_{4} \mathrm{OAc}$ to facilitate ${ }^{68} \mathrm{Ga}$-acetate chelation.

${ }^{67}$ Ga-acetate $(50 \mu \mathrm{L})$ or ${ }^{68} \mathrm{Ga}$-acetate $(500 \mu \mathrm{L})$ were mixed with Df-anti-HER2 scFv in $0.25 \mathrm{M}$ $\mathrm{NaOAc}(\mathrm{pH} 5.5)$ at room temperature for $5 \mathrm{~min}$. Following purification by using the PD-10 column, ${ }^{67 / 68} \mathrm{Ga}$-Df-anti-HER2 scFv was collected and used for further experiments. The radiochemical purity of the probes was determined by size-exclusion analysis using the PD-10 column. Size-exclusion high-performance liquid chromatography (SE-HPLC) was also performed (TSKgel SuperSW3000 [4.6 × 300 mm]; TOSOH Corporation, Tokyo, Japan; $100 \mathrm{mM}$ phosphate buffer [pH 6.6] containing $0.1 \mathrm{M} \mathrm{Na}_{2} \mathrm{SO}_{4}, 0.3 \mathrm{~mL} / \mathrm{min}$; wave length, $280 \mathrm{~nm}$ ).

In vitro stability

As described previously [17] with a slight modification, stability of ${ }^{67}$ Ga-Df-anti-HER2 scFv was tested in $25 \mathrm{mM} \mathrm{NaHCO} 3$ solution containing $5 \mathrm{mg} / \mathrm{mL}$ apo-transferrin. After incubation for $1,2,3$, and $24 \mathrm{~h}$ at $37^{\circ} \mathrm{C}, 50 \mu \mathrm{L}$ of the sample was collected for analysis by SE-HPLC. The eluent was collected every minute for $20 \mathrm{~min}$ and radioactivity was measured with an automatic well-type $\gamma$-counter (AccuFLEX $\gamma 7001 B$; Hitachi Aloka Medical, Ltd.; Tokyo, Japan). The retention time for apo-transferrin $(80 \mathrm{kDa})$, chicken ovalbumin $(44 \mathrm{kDa})$, anti-HER2 scFv (27 kDa), and horse myoglobin $(17 \mathrm{kDa})$ was $12.1,12.6,13.3$, and $14.0 \mathrm{~min}$, respectively.

The stability of the probe in mouse plasma was also determined. Animal studies were conducted in accordance with our institutional guidelines, and the experimental procedures were 
approved by the Kyoto University Animal Care Committee. Female BALB/c mice (5 weeks; 17-18

g) were purchased from Japan SLC, Inc. (Hamamatsu, Japan). Blood was withdrawn from the hearts of euthanized mice $(n=3)$ using heparinized syringes, and plasma was obtained by centrifugation at $1,000 \times g$ for $5 \mathrm{~min}$ at $4{ }^{\circ} \mathrm{C} .{ }^{67} \mathrm{Ga}$-Df-anti-HER2 $\mathrm{scFv}(20 \mu \mathrm{L})$ was incubated in mouse plasma $(100 \mu \mathrm{L})$ for $1 \mathrm{hr}$ at $37^{\circ} \mathrm{C}$, and then the sample was analyzed by SE-HPLC.

To determine the distribution ratio of ${ }^{67} \mathrm{Ga}$-Df-anti-HER2 scFv in plasma and blood cells, the probe $(20 \mu \mathrm{L})$ was incubated with mouse blood $(200 \mu \mathrm{L})$ for $1 \mathrm{hr}$ at $37^{\circ} \mathrm{C}$. After incubation, the blood was centrifuged at $1,000 \times g$ for $5 \mathrm{~min}$ at $4^{\circ} \mathrm{C}$ to separate plasma from blood cells. The radioactivity in each fraction was measured by the $\gamma$-counter.

\section{Cells and cell culture}

NCI-N87 human gastric cancer cells (N87) were obtained from American Type Culture Collection (Manassas, VA), and Suit-2 human pancreatic cancer cells were obtained from Human Science Research Resources Bank (Osaka, Japan). Both the cells were maintained in RPMI1640 medium supplemented with $10 \%$ fetal bovine serum, $0.6 \mathrm{mg} / \mathrm{mL} \mathrm{L-glutamine,} 1.8 \mathrm{mg} / \mathrm{mL} \mathrm{NaHCO}$, $100 \mathrm{U} / \mathrm{mL}$ penicillin, and $100 \mathrm{mg} / \mathrm{mL}$ streptomycin.

\section{Cell binding study}

N87 cells were plated in a 24 -well plate at $1 \times 10^{5}$ cells per well. After 18 -h incubation, the 
culture medium was replaced by a medium containing $0.1-50 \mathrm{nM}$ of ${ }^{67} \mathrm{Ga}-\mathrm{Df}$-anti-HER2 scFv and incubated for $2 \mathrm{~h}$ at $4{ }^{\circ} \mathrm{C}$. After the incubation, the medium was removed, and the cells were washed with PBS twice and lysed with $0.2 \mathrm{~N} \mathrm{NaOH}$. The radioactivity of each well was measured by $\gamma$-counter and was normalized using the protein concentration in each well, which was determined by using BCA protein assay kit (Pierce, Rockford, IL). The equilibrium dissociation constant $\left(\mathrm{K}_{\mathrm{D}}\right)$ was calculated using the GraphPad Prism software version 5.03 (GraphPad Software, Inc., La Jolla, CA).

Tumor model

Female BALB/c nude mice (5 weeks; 18-22 g) were purchased from Japan SLC, Inc. N87 and Suit- 2 cells $\left(5 \times 10^{6}\right.$ cells each in 50\% Geltrex Matrix [Life Technologies Corporation, Carlsbad, CA] in PBS) were subcutaneously transplanted into the right and left shoulders of the mice, respectively [18]. The mice were subjected to a tracer study at 4-6 weeks after the implantation. Before use, the tumor size was measured using a caliper, and the volume was calculated using the following equation: tumor volume $=$ length $\times(\text { width })^{2} / 2$ [19]. The average volume of N87 and Suit-2 xenografts was $150-250 \mathrm{~mm}^{3}$ and $200-400 \mathrm{~mm}^{3}$, respectively.

Biodistribution study

${ }^{67} \mathrm{Ga}-\mathrm{Df}-\mathrm{anti}-\mathrm{HER} 2 \mathrm{scFv}(30-50 \mathrm{kBq} / 0.81-1.35 \mu \mathrm{g}, 100 \mu \mathrm{L}$ in NaOAc buffer) was injected 
via the tail vein into the tumor-bearing mice $(n=4-5)$; the mice were dissected at 1,2 , and $3 \mathrm{~h}$ after the injection. Whole organs were immediately obtained and weighed, and their radioactivity was measured. The results are expressed in terms of the percent injected dose per gram of the tissue $(\% \mathrm{ID} / \mathrm{g})$.

Autoradiography and Immunohistochemistry

Tumor-bearing mice $(n=2)$ received intraveneous injection of ${ }^{67}$ Ga-Df-anti-HER2 scFv (3.7 MBq). The mice were sacrificed at $2 \mathrm{~h}$ after the injection, and the tumors were removed and frozen in hexane $\left(-80^{\circ} \mathrm{C}\right)$. The frozen tumor samples were cut into $20-\mu \mathrm{m}$-thick sections and adjacent 10 - $\mu \mathrm{m}$-thick sections. After 2-day exposure, autoradiograms were obtained, according to a previously described method $[20,21]$. The adjacent $10-\mu \mathrm{m}$ sections were subjected to immunohistochemical analyses for HER2 by using HercepTest (Dako, Denmark). Immunostaining was performed as per the manufacturer's protocol.

\section{PET imaging}

Tumor-bearing mice $(n=2)$ were intravenously injected with ${ }^{68} \mathrm{Ga}-\mathrm{Df}$-anti-HER2 scFv (9$24 \mathrm{MBq} / 52-65 \mu \mathrm{g}, 100 \mu \mathrm{L}$ in NaOAc buffer). At 1, 2, and $3 \mathrm{~h}$ after injection, the mice were imaged for $20 \mathrm{~min}$ by using eXplore VISTA (GE Healthcare Bio-Science). The acquisition and reconstruction of images were performed according to a previously described method [22]. After 
PET imaging, the mice were euthanized at approximately $3.25 \mathrm{~h}$ post injection. Tumors were immediately obtained and weighed, and their radioactivity was measured.

\section{Treatment protocol and in vivo monitoring of HER2 expression}

The mice $(n=9)$ were used for therapeutic study when their tumor volume reached approximately 100-300 $\mathrm{mm}^{3}$. Animals were divided in 3 groups (3 mice in each group). In one of the groups (vehicle-treated group), each animal received saline containing 10\% DMSO and 10\% ethanol, intravenously, once in a day for 3 consecutive days. The tumor size was monitored from Day 0 , when the animals received the $1^{\text {st }}$ dose of treatment to Day 14 . In the other groups, a dose of $50 \mathrm{mg} / \mathrm{kg}$ of 17-DMAG dissolved in saline containing $10 \%$ DMSO and $10 \%$ ethanol was administered via tail vein injection for 3 consecutive days (a total of $150 \mathrm{mg} / \mathrm{kg}$ of $17-\mathrm{DMAG}$ ). The tumor size was monitored from Day 0 to Day3 in 1 group and from Day 0 to Day14 in the other group. Tumor growth was monitored by caliper measurement, and tumor volume was calculated.

After the final measurement of tumor size in the 17-DMAG-treated groups, 2 mice from each group were subjected to PET/X-ray computed tomography (CT) imaging. The mice were intravenously injected with ${ }^{68} \mathrm{Ga}$-Df-anti-HER $2 \mathrm{scFv}$, and $2 \mathrm{~h}$ later, they were imaged for 20 min by using the FX3300 preclinical imaging system (Gamma Medica, Inc., Northridge, CA) under 2.5\% isoflurane anesthesia. Coincident data were collected for $511 \mathrm{keV}$ gamma rays with an energy window of 250-700 keV. PET images were reconstructed by using a 2-dimensional ordered-subset 
expectation maximization algorithm (iterations, 20; subsets, 4), and regions of interest (ROIs) were drawn on the tumors. CT scannings were performed according to a previously described method [23]. After PET/CT imaging, each tumor was removed and frozen for further analysis by using western blotting. Before frozen, the radioactivity and weight of the tumors were measured.

\section{Western blot}

Tumors were homogenized in Passive Lysis Buffer (Promega Corporation, Madison, WI) with 1\% Protease Inhibitor Cocktail (Sigma-Aldrich, Inc., St. Louis, MO). The homogenates were centrifuged at $15,000 \times g$ for $10 \mathrm{~min}$, and the supernatants were retained. The protein content was determined using the BCA protein assay kit. The supernatants were separated by sodium dodecylsulfate-polyacrylamide gel electrophoresis, and proteins were transferred to Immobilon PVDF membranes (Millipore Corporation, Billerica, MA). After blocking with Blocking One (Nacalai Tesque, Inc., Kyoto, Japan) for $30 \mathrm{~min}$, the membranes were probed with HER2 antibody (\#2242, Cell Signaling Technology, Inc., Danvers, MA) at $4^{\circ} \mathrm{C}$ for $12 \mathrm{~h}$. After washing 3 times with PBS containing $0.05 \%$ Tween20, anti-rabbit, horseradish peroxidase-linked antibody (\#7074, Cell Signaling Technology, Inc.) was allowed to react with the proteins at room temperature for $45 \mathrm{~min}$. All the antibodies were diluted 1:1000 with Can Get Signal (TOYOBO Co., Ltd., Osaka, Japan). After the washing step, the protein bands were visualized using Chemi-Lumi One Super (Nacalai Tesque, Inc.) with a gel imaging system (ChemiDoc XRS; BIO-RAD Laboratories, Hercules, CA). 
Immunoblotting with $\beta$-actin was used as a protein-loading control.

\section{Statistical Analyses}

Comparisons between the 2 groups were made using the Student's $t$-test. The analyses of the data from the therapeutic study were performed using 2-way analysis of variance (ANOVA) with repeated measures followed by a Tukey-Kramer multiple comparison test. A $P$ value of $<0.05$ was considered statistically significant.

\section{Results}

Preparation of ${ }^{67 / 68}$ Ga-Df-anti-HER2 scFv

The molecular weight of anti-HER2 scFv, Df-anti-HER2 scFv, and Ga-Df-anti-HER2 scFv was 27609.2, 27711.5, and 27771.2, respectively. This result indicates that $0.14 \mathrm{Df}$ was introduced into the $\mathrm{scFv}$ on the average, and is in accordance with a previous report $(0.2 \mathrm{Df}$ per nanobody molecule) [16].

The radiochemical yield of ${ }^{67} \mathrm{Ga}-\mathrm{Df}$-anti-HER2 $\mathrm{scFv}$ and ${ }^{68} \mathrm{Ga}$-Df-anti-HER2 scFv was $83 \%$ and $86 \%$, respectively. The radiochemical purity of both the probes was greater than $98 \%$; its adsorption in PD-10 column was insignificant. ${ }^{67}$ Ga-Df-anti-HER2 scFv was obtained in a single peak that corresponded to non-radioactive Ga-Df-anti-HER2 scFv by SE-HPLC. 


\section{Binding affinity}

The binding affinity of ${ }^{67}$ Ga-Df-anti-HER2 scFv was $9.94 \pm 1.36 \mathrm{nM}$. This value represents the mean \pm standard deviation of 3 examinations and is within the optimal range $(1-100 \mathrm{nM})$ at which significant tumor uptake is expected [24].

In vitro stability

The temporal changes in intact ${ }^{67} \mathrm{Ga}-\mathrm{Df}$-anti-HER2 $\mathrm{scFv}$ in apo-transferrin solution are shown in Table 1. The radiochemical purity of ${ }^{67} \mathrm{Ga}-\mathrm{Df}$-anti-HER2 scFv was maintained at levels greater than $95 \%$ after 3 -h incubation with transferrin-containing $\mathrm{NaHCO}_{3}$ solution. No radioactivity was eluted in the transferrin fractions. The recovery of radioactivity from the HPLC column was $92.6 \pm 6.4 \%$. After $24-\mathrm{h}$ incubation, the purity decreased to $48.1 \%$ and the recovery of radioactivity from the HPLC column was $77.5 \pm 7.4 \%$, suggesting that low-molecular weight byproducts were generated during 24-h incubation.

In mouse plasma, ${ }^{67} \mathrm{Ga}$-Df-anti-HER2 $\mathrm{scFv}$ was also stable. All radioactivity was eluted in the fraction of monomeric ${ }^{67} \mathrm{Ga}$-Df-anti-HER2 $\mathrm{scFv}$ after 1-h incubation in mouse plasma. The percentage of radioactivity distribution in plasma and blood cells was $84.4 \pm 1.0 \%$ and $15.6 \pm 1.0 \%$, respectively. 


\section{Biodistribution study}

The results of biodistribution study are presented in Table 2 . The highest radioactivity was observed to accumulate in the kidneys. The radioactivity in blood at $1 \mathrm{~h}$ was higher than that in the tumors, but it decreased in a time-dependent manner. The radioactivity in N87 tumor increased in a time-dependent manner and was the highest among that in all the organs examined at $3 \mathrm{~h}$, except for the kidneys. Significantly high radioactivity accumulated in N87 xenograft compared to that in Suit-2 xenograft at 2 and $3 \mathrm{~h}$ post injection. At $3 \mathrm{~h}$ post injection, the ratios of N87-to-blood, N87-to-Suit-2, and N87-to-muscle were $1.06 \pm 0.17,1.97 \pm 0.24$, and $7.92 \pm 5.57$, respectively.

\section{Autoradiography and Immunohistochemistry}

Figure 1 shows the autoradiograms and the images of immunostained sections. Immunostaining revealed high expression of HER2 in the N87xenograft but no expression in the Suit-2 xenograft. The radioactivity accumulated regions in N87 xenograft coincided with the HER2-positive regions. On the other hand, the radioactivity accumulation in Suit-2 xenograft was low and homogenous.

\section{PET imaging}

Decay-uncorrected, serial PET images are shown in Fig. 2. N87 xenografts could be visualized in all the images, although radioactivity in the heart and liver was also high at $1 \mathrm{~h}$ post 
injection, reflecting high radioactivity in blood. On the other hand, the radioactivity in Suit-2 xenografts was at background level at all the time points. The radioactivity in N87 and Suit-2 xenografts measured after dissection was $3.45 \% \mathrm{ID} / \mathrm{g}$ and $1.50 \% \mathrm{ID} / \mathrm{g}$, respectively. The ratio of N87-to-Suit-2 was 2.30 .

Therapeutic study

The effects of 17-DMAG on tumor growth and body weight are shown in Fig. 3. 17-DMAG is an inhibitor of heat shock protein 90 (Hsp90) and is effective in many cancers [25]. After treatment with 17-DMAG, the size of N87 xenograft initially decreased but increased again from Day 5 onwards. The growth of Suit-2 xenograft was delayed for 11 days. In contrast, both the xenografts in the vehicle-treated group continued to grow and increased in size by a factor of $2.5-4$ by Day 14 (Fig. 3a). Two-way ANOVA demonstrated significant effects of the treatment $\left(F_{3,48}=\right.$ 48.9; $P<0.0001)$ and time $\left(F_{5,48}=39.3 ; P<0.0001\right)$ and a significant interaction between treatment and time $\left(F_{15,48}=7.68 ; P<0.0001\right)$ was observed. The size of N87 and Suit-2 xenografts in 17-DMAG-treated mice was significantly smaller than that of the vehicle-treated mice $(P<0.01)$. The body weight was similar between the vehicle and 17-DMAG-treated groups at any time point (Fig. 3b).

Evaluation of HER2 expression by PET imaging and western blot analysis 
Figure 4 shows the images of PET and western blotting in the identical xenograft after treatment with 17-DMAG. We chose to perform PET images at $2 \mathrm{~h}$ post injection because the effects of high background radioactivity and radioactive decay were more pronounced at 1 and $3 \mathrm{~h}$ post injection, respectively. The N87 xenograft could be clearly observed in the control mouse, while the Suit-2 xenograft was not visible. On the day after 17-DMAG treatment was concluded (Day 3), the tumor shrank and radioactivity accumulation, determined by the dissection method and PET imaging was $33 \%$ and $31 \%$, respectively, as compared to that in control mice. Eleven days later (Day 14), radioactivity accumulation, determined by the dissection method and PET imaging was $66 \%$ and $75 \%$, respectively, compared to that in control mice (Fig. 4a). These changes were in accordance with the changes in the expression of HER2 detected by western blotting. The signal density of HER 2 normalized by $\beta$-actin was $29 \%$ and $76 \%$ compared to that of the control mice on days 3 and 14, respectively (Fig. 4b). There was no HER2 expression in the Suit-2 xenografts (data not shown).

\section{Discussion}

Although trastuzumab and its fragmented derivatives have been labeled by various radionuclides $[9,10,12,13]$, the pharmacokinetics of these probes was too slow to be labeled by short half-lived radionuclide, ${ }^{68} \mathrm{Ga}$. To our knowledge, there is only 1 report regarding 
${ }^{68}$ Ga-DOTA-conjugated antibody derivatives targeting HER2 [11]. The authors developed ${ }^{68}$ Ga-DOTA-F $\left(\mathrm{ab}^{\prime}\right)_{2}$-Herceptin and succeeded in performing the PET imaging of HER2-expressing tumor in mice. However, the condition of radiolabeling was unclear. Neither temperature, reaction time, nor radiochemical yield were mentioned in the manuscript. In fact, the radiochemical yield of ${ }^{68} \mathrm{Ga}$-DOTA-anti HER2 $\mathrm{scFv}$ was less than $5 \%$ after 1 -h incubation at room temperature in our preliminary experiment. On the other hand, rapid $(<5 \mathrm{~min})$ radiolabeling by ${ }^{67 / 68} \mathrm{Ga}$ was accomplished at room temperature with a high radiochemical yield (approximately $85 \%$ ) by using deferoxamine as a bifunctional chelating agent. Since the molecular size of scFv was smaller than that of $\mathrm{F}\left(\mathrm{ab}^{\prime}\right)_{2},{ }^{68} \mathrm{Ga}$-Df-anti-HER2 scFv showed faster blood clearance (scFv: $5.44 \% \mathrm{ID} / \mathrm{g}$ at $3 \mathrm{~h}$, $\mathrm{F}\left(\mathrm{ab}^{\prime}\right)_{2}:>15 \% \mathrm{ID} / \mathrm{g}$ at $\left.3.5 \mathrm{~h}\right)$ and better tumor-to-blood ratio ( $\mathrm{scFv}: 1.06$ at $3 \mathrm{~h}, \mathrm{~F}\left(\mathrm{ab}^{\prime}\right)_{2}:<1$ at $\left.3.5 \mathrm{~h}\right)$ than ${ }^{68}$ Ga-DOTA-F $\left(\mathrm{ab}^{\prime}\right)_{2}$-Herceptin did [11].

Recently, several protein-engineered, antibody-mimetic probes, called "affibody molecules" have been developed and labeled with ${ }^{68} \mathrm{Ga}$ to target and image HER2. Among them, 1 of the most promising probes is ${ }^{68} \mathrm{Ga}-\mathrm{ABY}-002$, which was used in humans for the first time and was successfully employed for imaging HER2-expressing tumors in breast cancer patients [26]. In preclinical experiment, ${ }^{68}$ Ga-ABY-002 showed approximately 2-fold higher accumulation (12.4\%ID/g at $2 \mathrm{~h}$ ) in HER2-positive xenografts compared to ${ }^{68} \mathrm{Ga}-\mathrm{Df}$-anti-HER2 scFv (5.21\%ID/g at $2 \mathrm{~h}$ ), although the xenografts were made by using different cell lines [27]. The accumulation of ${ }^{68} \mathrm{Ga}$-DOTA-MUT-DS (4.12\%ID/g at $\left.2 \mathrm{~h}\right)$ and ${ }^{68} \mathrm{Ga}-\mathrm{Z}_{\mathrm{HER} 2: 342 \mathrm{~min}}(2.40 \% \mathrm{ID} / \mathrm{g}$ at 2 h) in 
HER2-positive xenografts was comparable to that of ${ }^{68} \mathrm{Ga}-\mathrm{Df}$-anti-HER2 scFv at the same time point [28, 29]. However, both affibody probes showed better tumor-to-blood ratio than ${ }^{68} \mathrm{Ga}$-Df-anti-HER2 scFv. Therefore, structural modification of ${ }^{68} \mathrm{Ga}$-Df-anti-HER2 scFv is required to improve the blood ratio.

Although ${ }^{68} \mathrm{Ga}$-Df-anti-HER2 $\mathrm{scFv}$ showed faster blood clearance than radiolabeled trastuzumab and its fragmented derivative, the radioactivity of ${ }^{68} \mathrm{Ga}$-Df-anti-HER2 scFv in blood was higher than those of the other scFv probes [30,31]. Gallium is reported to form a complex with transferrin, which exists in blood [32]. However, from transferrin challenge studies in the presence of carbonate, we found that ${ }^{67} \mathrm{Ga}$-Df-anti-HER2 $\mathrm{scFv}$ was stable in the presence of apo-transferrin, without the occurrence of transchelation reaction with transferrin. Furthermore, ${ }^{67}$ Ga-Df-anti-HER2 $\mathrm{scFv}$ existed as an intact monomer in mouse plasma and showed no interaction with serum proteins.

These results correlate with high stability of the ${ }^{67 / 68}$ Ga-nanobody probe previously reported in human serum, using the same bifunctional chelating agent as in the present study [16]. Thus, slow blood clearance is not attributable to a transchelation reaction with transferrin followed by circulation of ${ }^{68} \mathrm{Ga}$-transferrin in blood, interaction with serum proteins, or dimerization. The reason for slow blood clearance of ${ }^{67} \mathrm{Ga}$-Df-anti-HER2 $\mathrm{scFv}$ still remains unclear. Some radioactivity existed in blood cell fractions, suggesting interaction between ${ }^{67} \mathrm{Ga}$-Df-anti-HER2 scFv and blood cells, and may be a possible reason for delayed blood clearance of ${ }^{67} \mathrm{Ga}-\mathrm{Df}$-anti-HER2 scFv.

Trastuzumab (Herceptin) has been approved for the treatment of HER2-positive breast 
cancer and metastatic gastric cancer $[33,34]$. Thus, the radioactivity ratios of tumor-to-thoracic and abdominal organs are important to evaluate HER2 expression by using ${ }^{68} \mathrm{Ga}$-Df-anti-HER2 scFv. The biodistribution study indicated that the highest radioactivity accumulated in the kidneys. Although tumor-to-stomach ratio was greater than 1, the high radioactivity in the kidneys may hamper the application of ${ }^{68} \mathrm{Ga}$-Df-anti-HER2 scFv for metastatic gastric cancer. However, it would interfere the least with the imaging quality of breast cancer, which is distant from the kidneys. Since the ratios of tumor-to-heart and lung were greater than 1 after $2 \mathrm{~h}$ post injection, ${ }^{68} \mathrm{Ga}$-Df-anti-HER2 $\mathrm{scFv}$ is capable of monitoring the HER2 expression of breast cancer noninvasively.

In PET study, the protein concentration of ${ }^{68} \mathrm{Ga}-\mathrm{Df}$-anti-HER2 $\mathrm{scFv}$ was approximately 50-fold higher than that of ${ }^{67} \mathrm{Ga}-\mathrm{Df}$-anti-HER2 $\mathrm{scFv}$ used for the biodistribution study. Although the tumoral accumulation of ${ }^{68} \mathrm{Ga}$-Df-anti-HER2 $\mathrm{scFv}$ in PET study was lower than that in biodistribution study, the radioactivity ratio of HER2-positive-to-negative xenografts was comparable in both the studies. Thus, the difference in the specific activity of the probe probably did not affect the probe distribution. Specific activity of ${ }^{68} \mathrm{Ga}-\mathrm{Df}$-anti-HER2 scFv used for PET study $(0.2-0.4 \mathrm{MBq} / \mu \mathrm{g})$ was comparable to that of other ${ }^{68} \mathrm{Ga}$-labeled probes $(0.4-0.6 \mathrm{MBq} / \mu \mathrm{g})$ that were successful in PET imaging of HER2-positive xenografts [27, 28]. Reduction of blood flow under anesthesia may cause low accumulation of ${ }^{68} \mathrm{Ga}$-Df-anti-HER2 scFv in PET study.

Hsp90 is a molecular chaperone that plays an important role in the maturation and stability of client proteins. Since HER2 is one of the most sensitive target proteins of Hsp90, it is expected 
that the Hsp90 inhibitors would be effective against HER2-overexpressing tumors [35]. Therefore, we used 17-DMAG for anti-HER2 therapy, which is the first Hsp90 inhibitor approved for clinical trials [36], and succeeded in monitoring HER2 status after therapy by noninvasive PET imaging. Chandarlapaty et al. reported that combined therapy of trastuzumab and a Hsp90 inhibitor was effective for treating trastuzumab-resistant breast cancer [37] and phase I dose-escalation clinical trial of trastuzumab and 17-DMAG were recently performed [38]. Since the anti-HER2 scFv used in this study recognizes the same epitope as trastuzumab, the monitoring of HER2 status during the combination therapy is unfortunately difficult. Affibody-based probes can overcome this issue because they bind to distinct epitopes on the HER2 extracellular domain, which is different from the binding site of trastuzumab [39].

\section{Conclusion}

By using deferoxamine as a bifunctional chelate, ${ }^{68} \mathrm{Ga}$-labeled scFv targeting HER2 was rapidly obtained under mild labeling conditions. ${ }^{68} \mathrm{Ga}$-Df-anti-HER2 scFv maintained its immunoreactivity and showed high accumulation in HER2-positive xenografts. The intratumoral distribution of radioactivity coincided with HER2-positive regions. Although low tumor-to-blood ratio needs to be improved, ${ }^{68} \mathrm{Ga}-\mathrm{Df}$-anti-HER2 $\mathrm{scFv}$ successfully visualized HER2-positive xenografts and monitored the changes in HER2 expression after therapy. Thus, ${ }^{68}$ Ga-Df-anti-HER2 
scFv could be a promising probe to evaluate HER2 status by in vivo PET imaging, unless trastuzumab is prescribed as part of the therapy. 


\section{Acknowledgments}

The authors would like to thank FUJIFILM RI Pharma Co., Ltd. for providing gallium-67 chloride and supporting the use of ${ }^{68} \mathrm{Ge} /{ }^{68} \mathrm{Ga}$ generator. The authors would like to thank Canon Inc. for providing anti-HER2 scFv. The authors are grateful to Central Research Laboratory, Okayama University Medical School for MALDI-TOF-MS analyses, and Okayama Medical Inovation Center for the assistance of image analyses. This work was supported in part by the Research and Development Project on Molecular Probes for Detection of Biological Features on Cancer of the New Energy and Industrial Technology Development Organization (NEDO), Japan, and a Grant-in-Aid for Scientific Research (KAKENHI No. 23000005) from the Japan Society for the Promotion of Science.

\section{Conflict of Interest}

The authors declare that they have no conflict of interest. 


\section{References}

1. Chua TC, Merrett ND (2012) Clinicopathologic factors associated with HER2-positive gastric cancer and its impact on survival outcomes--a systematic review. Int J Cancer $130: 2845-2856$

2. Stern HM (2012) Improving treatment of HER2-positive cancers: opportunities and challenges. Sci Transl Med 4:127rv122

3. McAlpine JN, Wiegand KC, Vang R, et al. (2009) HER2 overexpression and amplification is present in a subset of ovarian mucinous carcinomas and can be targeted with trastuzumab therapy. BMC Cancer 9:433

4. Nielsen DL, Kumler I, Palshof JA, Andersson M (2013) Efficacy of HER2-targeted therapy in metastatic breast cancer. Monoclonal antibodies and tyrosine kinase inhibitors. Breast $22: 1-12$

5. Sauter G, Lee J, Bartlett JM, Slamon DJ, Press MF (2009) Guidelines for human epidermal growth factor receptor 2 testing: biologic and methodologic considerations. J Clin Oncol $27: 1323-1333$

6. Warneke VS, Behrens HM, Boger C, et al. (2013) Her2/neu testing in gastric cancer: evaluating the risk of sampling errors. Ann Oncol 24:725-733

7. Fabi A, Di Benedetto A, Metro G, et al. (2011) HER2 protein and gene variation between primary and metastatic breast cancer: significance and impact on patient care. Clin Cancer 
Res 17:2055-2064

8. Capala J, Bouchelouche K (2010) Molecular imaging of HER2-positive breast cancer: a step toward an individualized 'image and treat' strategy. Curr Opin Oncol 22:559-566

9. Tamura K, Kurihara H, Yonemori K, et al. (2013) ${ }^{64} \mathrm{Cu}$-DOTA-Trastuzumab PET Imaging in Patients with HER2-Positive Breast Cancer. J Nucl Med 54:1869-1875

10. Dijkers EC, Oude Munnink TH, Kosterink JG, et al. (2010) Biodistribution of ${ }^{89} \mathrm{Zr}$-trastuzumab and PET imaging of HER2-positive lesions in patients with metastatic breast cancer. Clin Pharmacol Ther 87:586-592

11. Smith-Jones PM, Solit DB, Akhurst T, et al. (2004) Imaging the pharmacodynamics of HER2 degradation in response to Hsp90 inhibitors. Nat Biotechnol 22:701-706

12. Reddy S, Shaller CC, Doss M, et al. (2011) Evaluation of the anti-HER2 C6.5 diabody as a PET radiotracer to monitor HER2 status and predict response to trastuzumab treatment. Clin Cancer Res 17:1509-1520

13. Olafsen T, Kenanova VE, Sundaresan G, et al. (2005) Optimizing radiolabeled engineered anti-p185HER2 antibody fragments for in vivo imaging. Cancer Res 65:5907-5916

14. Decristoforo C, Pickett RD, Verbruggen A (2012) Feasibility and availability of ${ }^{68}$ Ga-labelled peptides. Eur J Nucl Med Mol Imaging 39 Suppl 1:S31-40

15. Jagoda EM, Lang L, Bhadrasetty V, et al. (2012) Immuno-PET of the hepatocyte growth factor receptor Met using the 1-armed antibody onartuzumab. J Nucl Med 53:1592-1600 
16. Vosjan MJ, Perk LR, Roovers RC, et al. (2011) Facile labelling of an anti-epidermal growth factor receptor Nanobody with ${ }^{68} \mathrm{Ga}$ via a novel bifunctional desferal chelate for immuno-PET. Eur J Nucl Med Mol Imaging 38:753-763

17. Boros E, Ferreira CL, Yapp DT, et al. (2012) RGD conjugates of the H2dedpa scaffold: synthesis, labeling and imaging with ${ }^{68} \mathrm{Ga}$. Nucl Med Biol 39:785-794

18. Shimizu Y, Temma T, Hara I, et al. (2014) Micelle-based activatable probe for in vivo near-infrared optical imaging of cancer biomolecules. Nanomedicine 10:187-195

19. Nakase I, Konishi Y, Ueda M, Saji H, Futaki S (2012) Accumulation of arginine-rich cell-penetrating peptides in tumors and the potential for anticancer drug delivery in vivo. $\mathrm{J}$ Control Release 159:181-188

20. Ueda M, Ogawa K, Miyano A, et al. (2013) Development of an oxygen-sensitive degradable Peptide probe for the imaging of hypoxia-inducible factor-1-active regions in tumors. Mol Imaging Biol 15:713-721

21. Ueda M, Fukushima T, Ogawa K, et al. (2014) Synthesis and evaluation of a radioiodinated peptide probe targeting alphavbeta6 integrin for the detection of pancreatic ductal adenocarcinoma. Biochem Biophys Res Commun 445:661-666

22. Kudo T, Ueda M, Konishi H, et al. (2011) PET imaging of hypoxia-inducible factor-1-active tumor cells with pretargeted oxygen-dependent degradable streptavidin and a novel ${ }^{18}$ F-labeled biotin derivative. Mol Imaging Biol 13:1003-1010 
23. Ono M, Cheng Y, Kimura H, et al. (2013) Development of Novel ${ }^{123}$ I-Labeled Pyridyl Benzofuran Derivatives for SPECT Imaging of beta-Amyloid Plaques in Alzheimer's Disease. PLoS One 8:e74104

24. Adams GP, Schier R, McCall AM, et al. (2001) High affinity restricts the localization and tumor penetration of single-chain fv antibody molecules. Cancer Res 61:4750-4755

25. Garcia-Carbonero R, Carnero A, Paz-Ares L (2013) Inhibition of HSP90 molecular chaperones: moving into the clinic. Lancet Oncol 14:e358-369

26. Baum RP, Prasad V, Muller D, et al. (2010) Molecular imaging of HER2-expressing malignant tumors in breast cancer patients using synthetic ${ }^{111} \mathrm{In}$ - or ${ }^{68} \mathrm{Ga}$-labeled affibody molecules. J Nucl Med 51:892-897

27. Tolmachev V, Velikyan I, Sandstrom M, Orlova A (2010) A HER2-binding Affibody molecule labelled with ${ }^{68} \mathrm{Ga}$ for PET imaging: direct in vivo comparison with the ${ }^{111}$ In-labelled analogue. Eur J Nucl Med Mol Imaging 37:1356-1367

28. Ren G, Zhang R, Liu Z, et al. (2009) A 2-helix small protein labeled with ${ }^{68}$ Ga for PET imaging of HER2 expression. J Nucl Med 50:1492-1499

29. Honarvar H, Jokilaakso N, Andersson K, et al. (2013) Evaluation of backbone-cyclized HER2-binding 2-helix affibody molecule for in vivo molecular imaging. Nucl Med Biol 40:378-386

30. Kondo N, Temma T, Shimizu Y, et al. (2013) Miniaturized antibodies for imaging 
membrane type-1 matrix metalloproteinase in cancers. Cancer Sci 104:495-501

31. Adams GP, McCartney JE, Tai MS, et al. (1993) Highly specific in vivo tumor targeting by monovalent and divalent forms of 741F8 anti-c-erbB-2 single-chain Fv. Cancer Res $53: 4026-4034$

32. El Hage Chahine JM, Hemadi M, Ha-Duong NT (2012) Uptake and release of metal ions by transferrin and interaction with receptor 1. Biochim Biophys Acta 1820:334-347

33. Pinto AC, Ades F, de Azambuja E, Piccart-Gebhart M (2013) Trastuzumab for patients with HER2 positive breast cancer: delivery, duration and combination therapies. Breast 22 Suppl 2:S152-155

34. Huang D, Lu N, Fan Q, et al. (2013) HER2 Status in Gastric and Gastroesophageal Junction Cancer Assessed by Local and Central Laboratories: Chinese Results of the HER-EAGLE Study. PLoS One 8:e80290

35. Ono N, Yamazaki T, Nakanishi Y, et al. (2012) Preclinical antitumor activity of the novel heat shock protein 90 inhibitor CH5164840 against human epidermal growth factor receptor 2 (HER2)-overexpressing cancers. Cancer Sci 103:342-349

36. Trepel J, Mollapour M, Giaccone G, Neckers L (2010) Targeting the dynamic HSP90 complex in cancer. Nat Rev Cancer 10:537-549

37. Chandarlapaty S, Scaltriti M, Angelini P, et al. (2010) Inhibitors of HSP90 block p95-HER2 signaling in Trastuzumab-resistant tumors and suppress their growth. Oncogene 
$29: 325-334$

38. Jhaveri K, Miller K, Rosen L, et al. (2012) A phase I dose-escalation trial of trastuzumab and alvespimycin hydrochloride (KOS-1022; 17 DMAG) in the treatment of advanced solid tumors. Clin Cancer Res 18:5090-5098

39. Kramer-Marek G, Gijsen M, Kiesewetter DO, et al. (2012) Potential of PET to predict the response to trastuzumab treatment in an ErbB2-positive human xenograft tumor model. J Nucl Med 53:629-637 
Table 1. In vitro stability of ${ }^{67} \mathrm{Ga}-\mathrm{Df}$-anti-HER2 scFv

Incubation time $(\mathrm{h}) \quad$ Intact form $(\%)$

1

$$
97.1 \pm 1.3
$$

2

$95.5 \pm 0.2$

3

$95.4 \pm 0.3$

24

$48.1 \pm 2.6$

Values are represented as mean \pm S.D. of 3 independent examinations. 
Table 2. Biodistribution of ${ }^{67} \mathrm{Ga}-\mathrm{Df}$-anti-HER2 $\mathrm{scFv}$ in tumor-bearing mice

Time after injection $(\mathrm{h})$

\begin{tabular}{|c|c|c|c|}
\hline Organ & 1 & 2 & 3 \\
\hline Blood & $10.87 \pm 1.07$ & $7.00 \pm 1.26$ & $5.44 \pm 1.36$ \\
\hline N87 xenograft & $4.57 \pm 1.78$ & $5.21 \pm 1.31 *$ & $5.58 \pm 0.86^{* *}$ \\
\hline Suit-2 xenograft & $3.25 \pm 0.88$ & $3.24 \pm 0.68$ & $2.90 \pm 0.76$ \\
\hline Muscle & $1.84 \pm 0.81$ & $1.22 \pm 0.31$ & $1.01 \pm 0.67$ \\
\hline Heart & $3.82 \pm 0.70$ & $2.87 \pm 0.46$ & $2.22 \pm 0.64$ \\
\hline Lung & $6.09 \pm 1.22$ & $3.89 \pm 0.92$ & $3.51 \pm 0.57$ \\
\hline Stomach & $2.17 \pm 1.19$ & $2.61 \pm 0.92$ & $1.89 \pm 0.95$ \\
\hline Spleen & $3.06 \pm 0.62$ & $2.50 \pm 0.75$ & $2.65 \pm 0.80$ \\
\hline Pancreas & $1.75 \pm 0.54$ & $1.61 \pm 0.55$ & $1.77 \pm 0.69$ \\
\hline Liver & $6.33 \pm 1.62$ & $5.71 \pm 0.77$ & $4.86 \pm 0.30$ \\
\hline Kidneys & $124.08 \pm 28.04$ & $129.68 \pm 14.78$ & $106.84 \pm 18.38$ \\
\hline Intestine & $3.26 \pm 0.40$ & $3.91 \pm 0.49$ & $5.15 \pm 0.44$ \\
\hline
\end{tabular}

Organ uptake values are expressed as percent injected dose per gram of tissue.

Values are represented as mean \pm S.D., $n=4-5$.

* indicates $P<0.05, * *$ indicates $P<0.01$ vs. Suit-2 xenograft at the same time point. 
Figure 1

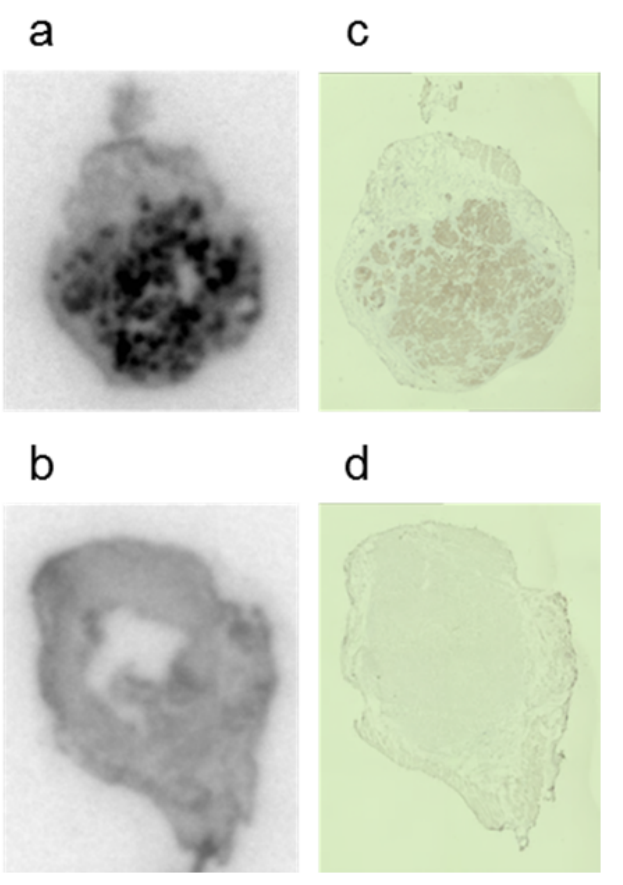

Representative images of autoradiograms and HER2 immunostainings in N87 (a, c) and Suit-2 (b,

d) xenografts. Strong HER2 expression was observed only in N87 xenograft (c). The radioactivity accumulation coincided with those regions (a). 


\section{Figure 2}

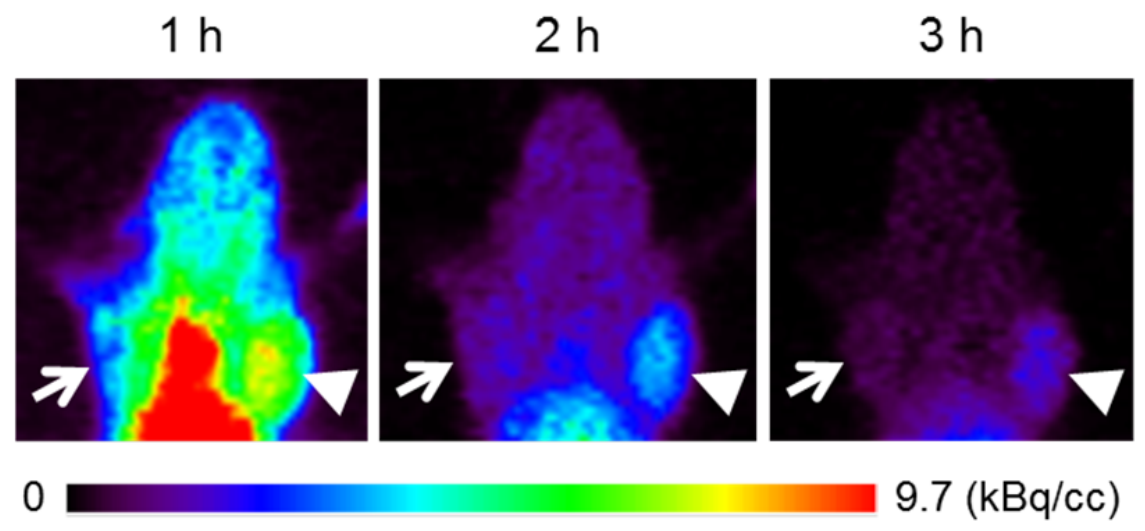

Representative PET images of N87- and Suit-2-implanted mice with ${ }^{68}$ Ga-Df-anti-HER2 scFv.

Images are shown at the same scale and not corrected by radioactive decay. Arrowheads and arrows indicate N87 and Suit-2 xenografts, respectively. 
Figure 3

a

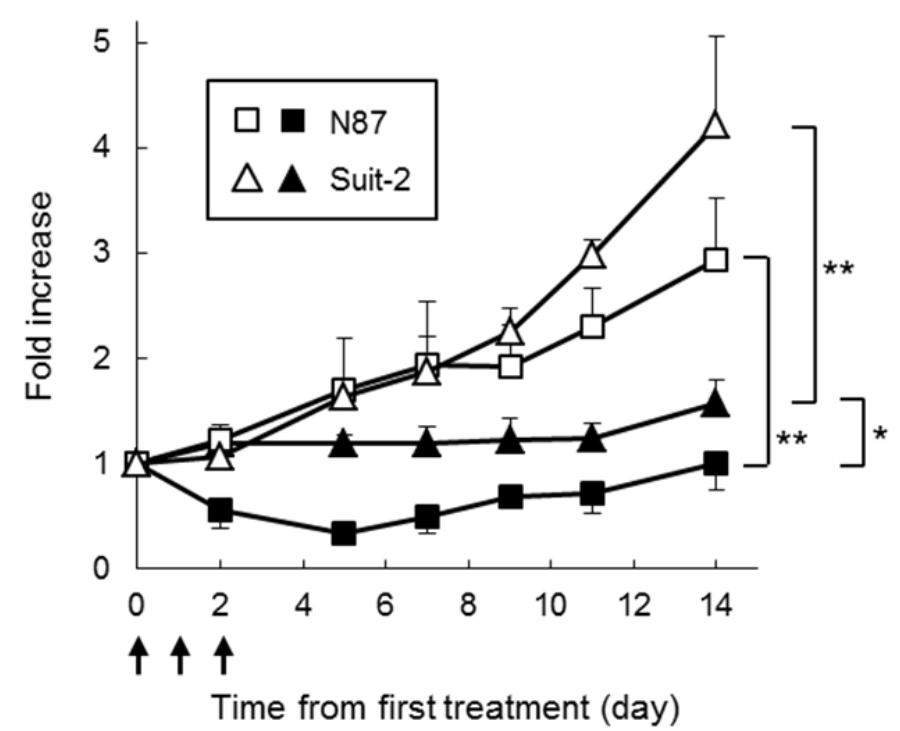

b

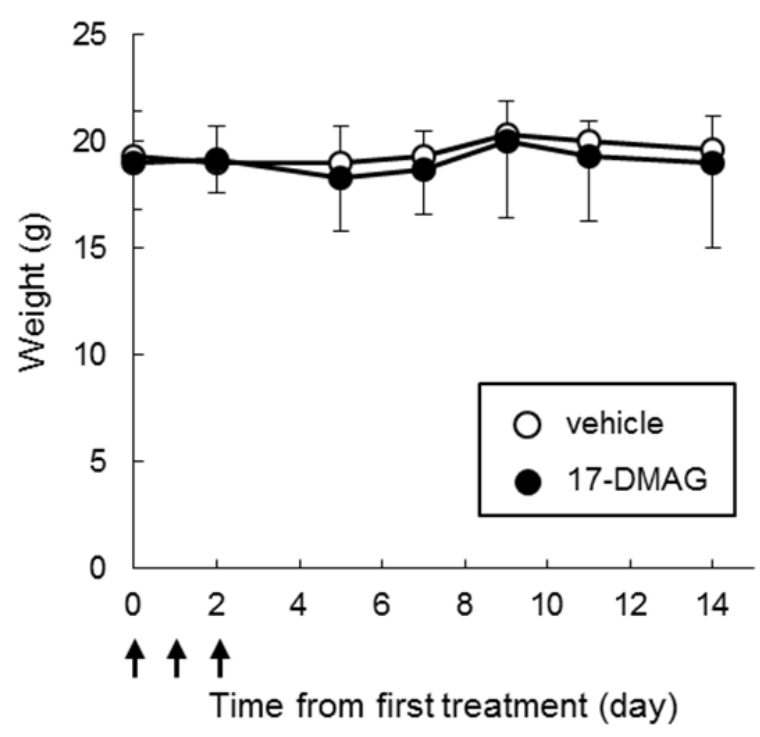

(a) Changes in the growth of N87 and Suit-2 xenografts of mice treated with vehicle or 17-DMAG.

Vehicle or 17-DMAG was injected once a day for 3 consecutive days, as indicated by the arrows.

Each data point represents an average of 3 mice, and each error bar represents the standard deviation. Open symbols represent data obtained from vehicle-treated mice and closed symbols represent those obtained from 17-DMAG-treated mice (* indicates $P<0.05$; ** indicates $P<0.01$ ). (b) Changes in body weight of mice treated with vehicle or 17-DMAG. Vehicle or 17-DMAG was injected once a day for 3 consecutive days, as indicated by arrows. Each data point represents an average of 3 mice and each error bar represents the standard deviation. There was no significant difference between the 2 groups. 


\section{Figure 4}

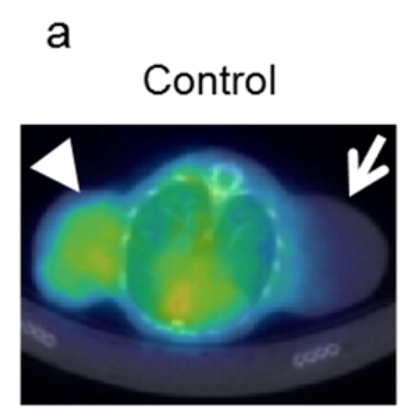

0
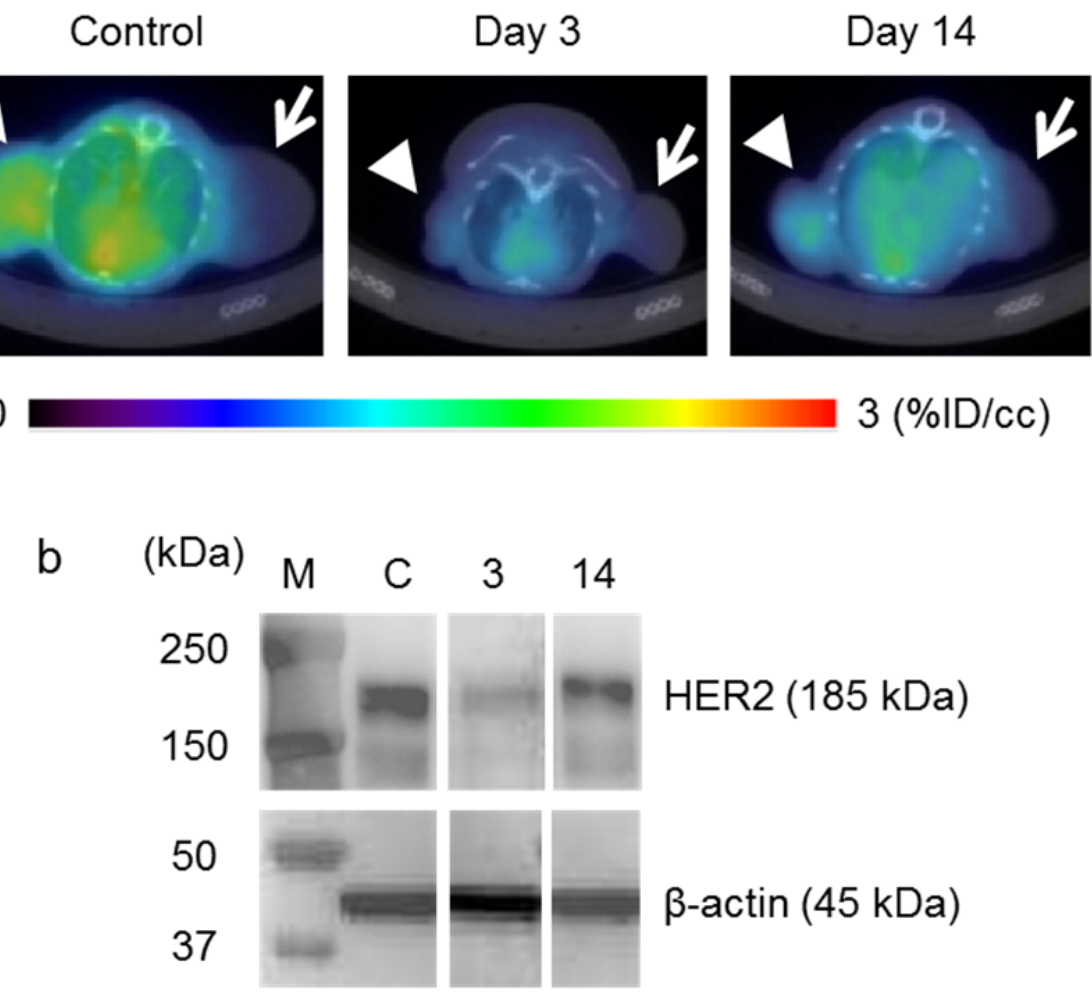

(a) Effect of 17-DMAG treatment assessed by PET images of N87- and Suit-2-implanted mice acquired at $2 \mathrm{~h}$ post injection of ${ }^{68} \mathrm{Ga}-\mathrm{Df}$-anti-HER $2 \mathrm{scFv}$. Arrowheads and arrows indicate N87 and Suit-2 xenografts, respectively.

(b) Western blot analysis of HER2 expression in N87 xenografts. The samples derived from control mice $(C)$ and 17-DMAG-treated mice (3 and 14) were analyzed. The numbers indicate the number of days from the initial administration of 17-DMAG. The bands of $\beta$-actin are shown as a protein-loading control. M, molecular size marker. 